\title{
DIDAKTIČNI IN STROKOVNI PRISPEVEK ALPSKIH MLADINSKIH RAZISKOVALNIH TABOROV V POSOČJU
}

\author{
Radovan Lipušček*
}

Izvleček

UDK 371.388:373.5(497.4 Posočje)

$V$ prispevku so predstavljeni namen in cilj alpskih mladinskih raziskovalnih taborov, način organiziranja ter oblike in metode dela na taboru. Prikazana je interdisciplinarnost dela na taborih, saj udeleženi mentorji in dijaki raziskujejo različna področja življenja in delovanja ljudi v pokrajini.

Ključne besede: tabor, ZOTKS, AMRT, dijaki, mentorji.

\section{DIDACTICAL AND PROFESSIONAL CONTRIBUTION OF THE ALPINE YOUTH RESEARCH CAMPS IN THE REGION OF POSOČJE}

\section{Abstract}

The paper emphasizes the purpose and the main goals of the Alpine Youth Research Camps in the region of Posočje, the way of organizing theme, forms and methods of work used on camps. Interdisciplinary activities on camps are presented with participants - mentors and students researching on different fields of life and work of people living in the region.

Key words : Camp, ZOTKS, AYRC, pupils, mentors.

\footnotetext{
${ }^{*}$ Prof. geog. in soc., Gimnazija Tolmin, Dijaška 12/b, 5220 Tolmin, Slovenija
} 


\section{UVOD}

Alpski mladinski raziskovalni tabori $\mathrm{v}$ Posočju so nastali na pobudo prvega organizatorja in vodje raziskovalnih taborov $\mathrm{v}$ Bovcu prof. dr. Jurija Kunaverja. Zamisel je nastala leta 1984 in je bila prvič uresničena v naslednjem letu. Vodje taborov dr. Jurij Kunaver, ravnatelj osnovne šole Podbrdo Aljoša Berginc in avtor te predstavitve smo $\mathrm{v}$ okrilju Zveze organizacij za tehnično kulturo Slovenije in koordinacijskega odbora Gibanja znanost mladini (ZOTKS - GZM) od prvega tabora v Bovcu organizirali dvanajst mladinskih raziskovalnih taborov. Tabora ni bilo le leta 1991 in pred organizacijo tabora v Baški grapi. Trinajst let je za neko nepoklicno dejavnost, kar poletni raziskovalni tabori vsekakor so, dolga doba. Njihov obstoj je izjemno pomemben za Tolminsko in tudi za celotno Zgornje Posočje, in to zaradi odsotnosti raziskovalnih ustanov, ki bi se ukvarjale s temeljnimi raziskavami v tem delu alpskega prostora Slovenije.

\section{NAMEN IN CILJI}

Poleg osnovnega namena, da bi o tej obrobni slovenski pokrajini, o kateri še vedno vemo premalo, čeprav ima bogato zgodovino in narodopisje in izredne naravne znamenitosti, pa je kljub temu doživelo v zadnjih časih prebivalstveno nazadovanje, ${ }^{1}$ izvedeli čim več, je bil namen organizacije tudi seznaniti mlade $\mathbf{z}$ raziskovalnimi metodami, ugotavljanjem in reševanjem znanstvenih problemov ter seveda druženje mladih iz vse Slovenije.

Misel dr. Kunaverja nas je vodila pri organizaciji vseh taborov, saj smo vedno raziskovali področja, ki v strokovni literaturi niso dovolj znana. Da je bilo opravljeno delo na taborih nujno potrebno, se je pokazalo pri delu in tudi v zanimanju, ki so ga ljudje pokazali, ko so ugotavljali, da je prav, da nekdo najprej razišče in nato tudi napiše kaj o pokrajini in ljudeh v njej. Okolje, v katerem so mladi raziskovalci živeli in delali, jih je zaradi tega lepo sprejelo.

$\mathrm{Ob}$ tem smo dosegli še druge cilje in smotre:

- mentorji so izpopolnili svoja znanja, saj so morali ob pripravah na tabor in kasneje pri delu na taboru obnoviti in spoznati metode raziskovalnega dela,

- spodbudili smo domačine, da so pridobili podatke o sedanjosti in preteklosti kraja,

\footnotetext{
${ }^{1}$ Kunaver dr.Jurij
} 
- $\quad$ spodbudili zavest pri domačinih, da obstaja določeno družbeno, zgodovinsko in naravno bogastvo v krajih, kjer živijo,

- udeleženci so podrobneje spoznali okolje $\mathrm{v}$ času neuradnega dela tabora (na izletih, obiskih delovnih organizacij, muzejev, kraških jam ipd.).

\section{ORGANIZACIJA TABOROV}

Ker je alpski in predalpski prostor $\mathrm{v}$ območju Zgornjega Posočja zelo pester in obsežen, smo se odločili izvesti tabore v različnih krajih.

Tabela 1: Osnovni podatki o vseh dosedanjih taborih

\begin{tabular}{|l|l|l|l|}
\hline Sedež tabora & Območje raziskovanja & Leta & Vodja \\
\hline Bovec & Bovška kotlina & $1985-1987$ & dr. Jurij Kunaver \\
\hline Tolmin & Dolini Tolminke in Zadlašice & $1988-1990$ & prof. Radovan Lipušček \\
\hline Podbrdo & Dolina Bače / Baška grapa & $1992-1995$ & $\begin{array}{l}\text { prof. Radovan Lipušček in } \\
\text { Aljoša Berginc }\end{array}$ \\
\hline Dolenja Trebuša & $\begin{array}{l}\text { Dolini Idrijce in Trebušice s } \\
\text { pritoki }\end{array}$ & $1996-1998$ & prof. Radovan Lipušck \\
\hline
\end{tabular}

Vir: Arhiv AMRT

Bolj kot dodatni vir za zaslužek, kajti dobili so le povrnjene materialne stroške udeležbe na taboru, so motivi organizatorjev in mentorjev za delo na mladinskih raziskovalnih taborih njihova potreba po raziskovalni dejavnosti, veselje do takega dela in želja po ustvarjalnosti. Večina taborov je bila organizirana v mesecu avgustu, ker se je pokazalo, da je takrat vreme za njihovo izvedbo najugodnejše. Za organizatorje taborov se delo začne že spomladi, ko se je treba $\mathrm{z}$ mentorji in uporabniki raziskav dogovoriti o programih in vsebinah dela na taboru. Tem so nato podrejene priprave, delo in njegov potek.

Po dogovoru vodje tabora $\mathrm{z}$ mentorji in omenjenimi ustanovami pride na vrsto dogovarjanje s financerji, sponzorji in drugimi, ki tako ali drugače sodelujejo pri delu tabora. Koordinacijski odbor Gibanja znanost mladini pri ZOTKS skrbi za razpošiljanje prijavnic in programov taborov po šolah in za zbiranje prijav. Vodstvo tabora pripravi tudi podrobnejše informacije bodočim udeležencem na taboru. Pomemben delež za uspešen potek dela imata nastanitev udeležencev in prehrana. To dvoje je pogoj za nemoteno strokovno delo. Zahvaljujoč razumevanju okolja je bil pri organizaciji naših taborov ta del hitro in uspešno rešen. Bivanje so nam nudili Rekreacijski center nekdanje JNA v Bovcu, Center za izobraževanje in usposabljanje Tolmin, Dom upokojencev Podbrdo in večnamenski objekt v Dolenji Trebuši. Hrano pa so nam pripravljali v bovških gostinskih obratih, dijaškem domu v Tolminu, domu 
upokojencev Podbrdo in $\mathrm{v}$ domači gostilni $\mathrm{v}$ Dolenji Trebuši. Tako $\mathrm{v}$ Bovcu, Tolminu, Podbrdu in Dolenji Trebuši so delovne prostore nudile šole, ki so tako opravile svojo vlogo tudi v času poletnih počitnic. Poleg ZOTKS, ki nosi največje finančno breme, smo k materialni podpori pritegnili še občino Tolmin, razne zavode (Gimnazijo Tolmin, Dijaški dom idr.), trgovska in gostinska podjetja in slovensko vojsko, ki so s svojimi prispevki vsak po svoje pripomogli k boljši opremljenosti udeležencev na taborih.

Čeprav naj bi na taborih dosegali največje učinke z uporabo preprostih tehničnih sredstev, smo na AMRT skrbeli za stalno izboljšavo raziskovalne tehnologije. Že na prvem taboru 1985 smo imeli na razpolago računalnik Spectrum 48K, na drugem osebni računalnik Commodore 64, na tretjem pa že prvi PC. Danes si dela brez računalnikov ne moremo več zamisliti, saj so vsi končni zapiski in rezultati pripravljeni in spravljeni na disketah, kar močno olajšuje hitro in kakovostno objavo rezultatov.

Ker je na taboru zelo pomembna avdiovizualna predstavitev rezultatov, smo tako $\mathrm{v}$ Bovcu kot $\mathrm{v}$ Tolminu uporabljali fotografske aparate in se posluževali fototemnic $\mathrm{v}$ šolah. Marsikateri udeleženec se je prav na taboru prvič seznanil z izdelavo črnobelih fotografij. $\mathrm{Na}$ zadnjih taborih pa smo fotodokumentacijo razvijali $\mathrm{v}$ profesionalnih ustanovah. Fotografije smo s pomočjo skenerjev digitalizirali in jih tako pripravili za objavo.

Poleg ročnega zapisovanja so pri beleženju informacij predvsem jezikovna, zgodovinska in etnološka skupina uporabljale kasetofone. Na zadnjih taborih smo imeli na razpolago videokamero, posneto delo na terenu pa je bilo nato predvajano na predstavitvah. Dijaki so se vključili v pripravo scenarija in montažo posnetega materiala. Nastala sta videofilma o dolini Tolminke in Zadlašice ter o življenju in delu ljudi v Baški dolini.

\section{UDELEŽENCI}

$\mathrm{Na}$ vseh dosedanjih taborih ni bilo težav z udeležbo dijakov in mentorjev. Mentorji so bili poleg dr. Jurija Kunaverja s Filozofske fakultete Univerze v Ljubljani, predvsem učitelji Gimnazije v Tolminu, osnovnih šol v Tolminu, na Mostu na Soči, na Dobrovem in $\mathrm{v}$ Podbrdu. Tesne povezave $\mathrm{z}$ Goriškim muzejem so omogočile udeležbo etnologov. Na taborih v Podbrdu in Dolenji Trebuši pa so pomagali mladi raziskovalci $z$ raznih inštitutov na SAZU in FF.

Tabela 1 Število udeležencev na Alpskih mladinskih raziskovalnih taborih 


\begin{tabular}{|l|c|c|c|c|c|}
\hline kraj & mentorjev & $\begin{array}{c}\text { pomočniki } \\
\text { mentorjev }\end{array}$ & dijakov & študentov & drugi udeleženci \\
\hline BOVEC & 8 & 4 & 76 & & 4 Poljaki \\
\hline TOLMIN & 11 & 2 & 63 & 16 & 3 učenci OŠ \\
\hline PODBRDO & 8 & 2 & $\operatorname{nad} 26$ & 5 & \\
\hline TREBUŠA & 7 & 1 & 22 & 2 & \\
\hline
\end{tabular}

Vir: Arhiv AMRT

Poleg srednješolcev, ki jim je bila udeležba na taborih nagrada za raziskovalno delo v šoli, so na taborih v Posočju sodelovali tudi študenti in učenci osmih razredov osnovnih šol. Srednješolci so prihajali iz vse Slovenije, predvsem pa iz bolj oddaljenih krajev. Udeležba iz severovzhodnega dela Slovenije, Bele krajine ipd. kaže na to, da želijo dijaki spoznavati kraje, ki so jim oddaljeni in neznani. Nekateri so se vračali na tabor večkrat. Tudi ta ugotovitev je vodila organizatorje, da so $\mathrm{z}$ delom nadaljevali.

Študenti, ki so se udeležili taborov, so bili dobrodošla pomoč mentorjem pri delu in v prostem času. Sodelovanje na taborih je zanje najboljša praksa in bogata izkušnja za bodoče pedagoško ali raziskovalno delo.

\section{VSEBINA RAZISKOVALNEGA DELA}

Vsebina raziskovalnega dela je bila večinoma podrejena zanimanju mentorjev. Vsi dosedanji tabori so bili interdisciplinarni, kar je dodatno obogatilo znanje vseh udeležencev.

Dijaki so sodelovali v skupinah z naslednjimi vsebinami raziskovanja:

- fizočnogeografska: snežni plazovi, podnebne posebnosti, naravna dediščina, geomorfološke značilnosti;

- geološka: terensko zbiranje in analiza vzorcev kamnin, kartiranje;

- družbenogeografska: izraba tal, struktura in dinamika poselitve, gostinska ponudba, obmejnost, demografska ogroženost ipd.;

- jezikoslovna in imenoslovna skupina: bovški, tolminski, trebuški govor in govor zgornjega dela Baške doline, zbiranje besed za slovar vseh teh narečij, zemljepisna imena;

- etnološka - materialna kultura: etnološka podoba predmetov, planinsko pašništvo, nabiralništvo;

- etnološka - duhovna kultura: pripovedništvo, pravljice, običaji ob rojstvu in smrti; 
- zgodovinska: Soška fronta, čas pod italijansko okupacijo, druga svetovna vojna, interniranci, kulturna dediščina, zgodovina krajev;

- fizikalna: fizikalne meritve na reki Tolminki;

- biološka: raziskave rastlinstva in vegetacijskih združb po standardni srednjeevropski metodi;

- kemijska: onesnaženost voda;

- arheološka: sondažne preiskave potencialno novih najdišč iz časa kovinske in rimske dobe.

\section{OBLIKE IN METODE DELA NA TABORIH}

Metode dela so pri vseh skupinah podrejene vsebini in ciljem raziskovanja. V skupinah, ki so delovale v okviru naših taborov, so uporabljali predvsem:

- anketiranje in intervju,

- zapisovanje, skiciranje,

- kartiranje,

- fotografiranje in snemanje z videokamero,

- opazovanja in

- specifične metode, ki jih uporabljajo omenjene znanosti.

Bistvena značilnost dela vseh skupin je bilo skupinsko delo. Uspešnost dela skupine pa je odvisna predvsem od osebne motiviranosti in angažiranosti mentorja. 


\section{REZULTATI DELA DOSEDANJIH 12.AMRT}

Zanimanje raznih institucij in posameznikov za naše delo je potrdilo naše prepričanje, da delamo prav in da so izsledki raziskav zanimivi tudi za širšo javnost. Objavljanje delnih rezultatov na koncu posameznih taborov se vodstvu taborov ni zdelo smotrno, zato smo se odločili za končno objavo rezultatov $\mathrm{v}$ posebnih zbornikih na koncu triletnega raziskovanja.

Prva publikacija je bila Pokrajina in ljudje na Bovškem, ki je izšla leta $1988 \mathrm{v}$ nakladi 500 izvodov. Avtorji - mentorji ali njih pomočniki - so v njej zaokrožili vsa nova spoznanja, ki so bila plod njihovega dela z mladimi na terenu. Sledil je zbornik Dolina Tolminke in Zadlašce, ki je izšel leta 1993 v nakladi 600 izvodov in je bil izdan $\mathrm{v}$ sodelovanju $\mathrm{z}$ upravo Triglavskega narodnega parka. Urednika obeh zbornikov sta bila vodji taborov. $\mathrm{V}$ drugem zborniku so zbrani tudi neobjavljeni prispevki avtorjev, ki na taborih niso sodelovali, so pa želeli objaviti svoje prispevke, ki so bili vsebinsko povezani s tem območjem. Za tabore, organizirane v Podbrdu, še čakamo ustrezno izdajo. Decembra 1994 je izšla brošura ${ }^{2}$ s poročili o delu na taboru leta 1993. Rezultat dela mentorja in geološke skupine na taborih v Dolenji Trebuši je viden v diplomskem delu mentorja Saša Šturma z naslovom Mineraloške preiskave surovin in stekel iz steklarne (1722-1741) v dolini Trebušice. Ko bodo raziskave končane, bo tudi za to področje izdelan ustrezen zbornik.

$\mathrm{V}$ vseh publikacijah bi lahko izbrali strokovne vsebine, ki so prispevale $\mathrm{k}$ novim spoznanjem. Navajanje vseh ugotovitev bi preseglo okvir tega prispevka, zato naj navedem le nekatere. Prispevki geografov so bili v vseh publikacijah dokaj obsežni in popolni. S taborov v Bovcu je bil odmeven prispevek avtorja tega prispevka o snežni plazovih, ki je postal osnova strokovnim podlagam za obnovo ceste $\mathrm{v}$ Trento in načrtom za HE Učja. O dolini Tolminke in Zadlašice je $\mathrm{k}$ novim spoznanjem največ prispevala geomorfološka razprava o tamkajšnjih raziskovanjih izpod peresa dr. Jurija Kunaverja. O Baški dolini je najmočnejši prispevek s strani imenoslovne skupine, ki jo je vodil prof. Silvo Torkar, o Dolenji Trebuši pa že omenjeno diplomsko delo Saša Šturma.

\footnotetext{
${ }^{2} 8$. Alpski mladinski raziskovalni tabor Podbrdo 1993
} 


\section{PREDSTAVITVE REZULTATOV RAZISKOVANJ IN ARHIVIRANJE} RAZSTAVNEGA GRADIVA

Rezultate raziskovanj smo predstavljali tudi na razstavah in v letnih poročilih.

Predstavitev rezultatov $\mathrm{s}$ priložnostno razstavo in razgovorom $\mathrm{z}$ domačini ob otvoritvi je tisti del tabora, ki daje udeležencem največ dela, pa tudi največ zadovoljstva, če je predstavitev uspešna. Razstave smo pripravljali v prostorih KS, trgovskega podjetja $\mathrm{v}$ Bovcu, $\mathrm{v}$ knjižnici Cirila Kosmača $\mathrm{v}$ Tolminu, v veliki predavalnici ŠC v Tolminu, v osnovni šoli Podbrdo in večnamenski dvorani v Dolenji Trebuši. Obisk razstav je bil odvisen od možnosti varovanega ogleda. Na zadnjem taboru razstave ni bilo, ker je potekala predstavitev z internetno stranjo ${ }^{3}$, s katero smo obiskovalcem predstavili rezultate raziskav zadnjih let.

Arhiviranje izdelkov $\mathrm{s}$ taborov je odvisno od vodje in mentorjev. Evidenco o zbranem materialu bi morali imeti na ZOTKS, v pokrajinskih arhivih, v lokalnem muzeju ali drugih zavodih. Organizatorji AMRT smo se odločili, da bodo vsi izdelki raziskovalnih taborov v Zgornjem Posočju imeli prostor v geografski učilnici srednje šole v Tolminu. To pa zato:

- da bi morebitno nadaljnje raziskovanje ne pomenilo popolnega začetka pri zbiranju gradiva,

- da bi mentorji imeli čim pogostejši in čim lažji dostop do izdelkov in

- da bi mladi v šoli spoznali delo vrstnikov na taborih in bi jih to lahko motiviralo za uspešno delo pri pouku in tudi za udeležbo na taborih.

\section{SKLEP}

Stalno spremljanje in vrednotenje dogajanja $\mathrm{v}$ prostoru ter odkrivanje nekaterih dejstev imajo velik pomena pri načrtovanju razvoja mejnih, demografsko ogroženih področij. Ta lahko na ta način pridejo do podatkov, ki so lahko podlaga za usmerjanje razvoja $v$ bogatejšo in uspešnejšo prihodnost. Velikega pomena je tudi bogatitev našega vedenja o preteklosti. Nekatera pričevanja, zbrani dokazi in gradivo so neprecenljive vrednosti, saj nam lahko povedo marsikaj o tem, kako je človek $\mathrm{v}$ alpskem svetu živel in tudi preživel vsa ta stoletja. Na raziskovalnih taborih opozarjamo na probleme, ki se jih močno zavedamo, ne moremo jih pa vedno sami reševati. Navzočnost javnih občil, ki $\mathrm{v}$ času taborov pišejo in poročajo o delu, pripomore $\mathrm{k}$ aktualizaciji in uzaveščanju raziskovalnih vsebin.

\footnotetext{
${ }^{3}$ www.s-gimtol.go.edus.si (poglavje o raziskovalnih taborih)
} 
Na teh taborih mladi dokazujejo, da motivirani in pod dobrim strokovnim vodstvom lahko izpeljejo zaupano jim raziskovalno nalogo. To dosegajo $\mathrm{z}$ opisanimi metodami dela, ki so jim zanimivejša od tistih v šoli. Pridobljena znanja so tudi trajnejša od tistih, ki jih dobijo v šolah. Metode raziskovalnega dela na taborih obnovijo tudi učitelji, saj jih bodo morali v bodoči bolj ustvarjalni šoli skupaj z dijaki pogosteje uporabljati. Ne nazadnje je to priložnost za učitelje, da si pridobijo ovrednoteno strokovno izpopolnjevanje.

$\mathrm{S}$ tem prispevkom sem želel predstaviti nekaj možnosti, ki jih ponuja okolje $\mathrm{v}$ alpskem in predalpskem prostoru, pri bolj kakovostnem dojemanju tega prostora pri mladih in pri tvornejšem odnosu do pokrajine in ljudi v njej.

\section{LITERATURA IN VIRI}

1. Arhiv Alpskih mladinskih raziskovalnih taborov, Tolmin.

2. Berginc A., 1994: 8. Alpski mladinski raziskovalni tabor Podbrdo'93. ZRC SAZU in OŠ Podbrdo, Podbrdo.

3. Kunaver J., 1988: Pokrajina in ljudje na Bovškem. Zbornik, ZOTKS, Ljubljana.

4. Lipušček R., 1993: Tolminka in Zadlašca. Zbornik, ZOTKS, TNP, Tolmin. 


\section{DIDAKTIČNI IN STROKOVNI PRISPEVEK ALPSKIH MLADINSKIH RAZISKOVALNIH TABOROV V POSOČJU}

\section{Povzetek}

Alpske mladinske raziskovalne tabore organiziramo v krajih Zgornjega Posočja od leta 1985. Organizirani so s pomočjo državnih in lokalnih skupnosti. Sedež tabora je bil v Bovcu, Tolminu, Podbrdu in Dolenji Trebuši, raziskave pa so potekale v širši in ožji okolici (Bovško, Dolini Tolminke in Zadlašce, Baška grapa, dolina Trebušice).

Namen organizacije taborov je $\mathrm{v}$ druženju sposobnih mladih raziskovalcev iz vse Slovenije ter njihovem seznanjanju z demografsko ogroženo obmejno pokrajino $\mathrm{v}$ alpskem in predalpskem prostoru. Pod mentorskim vodstvom jim omogočamo tudi spoznavanje znanstvenih metod pri ugotavljanju in reševanju problemov.

Ob tem so bili doseženi še naslednji cilji:

- mentorji so izpopolnili svoja znanja in prišli do dodatnih izkušenj,

- pri domačinih se je spodbudila zavest o obstoju določenega družbenega, zgodovinskega in naravnega bogastva, ki ga je potrebno ohraniti,

- udeleženci taborov so kraj bivanja in območje raziskav spoznali tudi v času neuradnega dela tabora (na izletih, obiskih delovnih organizacij, muzejev, kraških jam ipd.).

Tabori so bili interdisciplinarni, saj so bili udeleženci vključeni $\mathrm{v}$ jezikovne, zgodovinske, geografske, etnološke, geološke, biološke, kemijske, fizikalne, arheološke in druge skupine.

Vsebine raziskovanj so bile določene $\mathrm{v}$ vodstvu taborov in prilagojene potrebam mentorjev in posameznih strok. Največ pa se je delalo na ohranjanju in zbiranju tistega, kar bi utegnilo iti v pozabo.

V referatu so predstavljeni tudi potek priprav na tabor, njegova tehnična priprava in nato tudi izvedba.

V zadnjem delu pa so predstavljeni načini objave rezultatov dela na taborih. 